Revista Brasileira de Agricultura Irrigada v.8, no. 1, p. 38 - 51, 2014

ISSN 1982-7679 (On-line)

Fortaleza, CE, INOVAGRI - http://www.inovagri.org.br

DOI: $10.7127 /$ rbai.v8n100185

Protocolo 185/13 - 26/09/2013 Aprovado em 14/01/2014

\title{
COEFICIENTES DE SENSIBILIDADE AO DÉFICIT HÍDRICO PARA A CULTURA DO GIRASSOL NAS CONDIÇÕES DO SEMIÁRIDO CEARENSE ${ }^{1}$
}

\author{
Alexandre Reuber Almeida da Silva ${ }^{2}$, Francisco Marcus Lima Bezerra ${ }^{3}$, Cley Anderson Silva \\ de Freitas ${ }^{4}$, Aiala Vieira Amorim ${ }^{5}$, Lilian Cristina Castro de Carvalho ${ }^{6}$, João Valdenor Pereira \\ Filho $^{2}$
}

\section{RESUMO}

Com o objetivo de determinar os coeficientes de sensibilidade ao déficit hídrico $\left(\mathrm{K}_{\mathrm{Y}}\right)$ da cultura do girassol nos estádios isolados e no ciclo total da cultura para as condições do semiárido cearense, um experimento de campo foi conduzido no município de Pentecoste, Ceará. O delineamento experimental adotado foi o de blocos ao acaso, com quatro repetições e oito tratamentos, definidos em função da época de indução do déficit hídrico nos três estádios fenológicos do girassol (vegetativo, floração e formação da produção), correspondendo à ocorrência de déficit hídrico em um, dois ou três estádios. O déficit correspondeu à aplicação da metade da dose de irrigação do tratamento sem déficit hídrico. Os valores de $\mathrm{K}_{\mathrm{Y}}$ foram obtidos através da relação entre a queda de rendimento relativo e o déficit de evapotranspiração relativa, conforme o método de Doorenbos e Kassam. As evapotranspirações (potencial e da cultura) foram calculadas pelo método do balanço hídrico no solo. Os resultados mostraram que, a sensibilidade ao déficit hídrico variou na seguinte ordem decrescente: formação da produção, vegetativo e floração, para déficit aplicado em apenas um estádio fenológico. Para as condições de déficit em dois estádios, o coeficiente $\mathrm{K}_{\mathrm{Y}}$ indicou que a insuficiência de água exerce maior impacto sobre o rendimento de aquênios do girassol quando ocorre simultaneamente nos estádios vegetativo e de formação da produção.

\footnotetext{
${ }^{1}$ Extraído da Dissertação de Mestrado apresentada pelo primeiro autor ao Programa de Pós-Graduação em Engenharia Agrícola da Universidade Federal do Ceará (UFC). Fortaleza, Ceará, Brasil

${ }^{2}$ Engenheiro Agronômo, Mestre em Engenharia Agrícola, Departamento de Engenharia Agrícola/CCA/UFC, Campus do Pici - Bloco 804, CEP 60.455-760, Fortaleza, Ceará, Brasil. alexandre_reuber@ hotmail.com; joao_valdenor@hotmail.com

Engenheiro Agronômo, Doutor em Agronomia/ Irrigação e Drenagem, Departamento de Engenharia Agrícola/CCA/UFC, Campus do Pici - Bloco 804, CEP 60.455-760, Fortaleza, Ceará,Brasil. mbezerra@ ufc.br

${ }^{4}$ Engenheiro Agronômo, Doutor em Engenharia Agrícola, Instituto Federal de Educação, Ciência e Tecnologia do Ceará, Campus avançado de Tianguá, Rodovia CE - 187, s/n, Aeroporto, CEP 62.320-000 Tianguá, Ceará, Brasil.anderson_agrotec@yahoo.com.br

${ }^{5}$ Bióloga, Doutora em Agronomia/ Fitotecnia, Universidade da Integração Internacional da Lusofonia AfroBrasileira, Campus da Liberdade, Avenida da Abolição, nº 3, Centro, CEP 62.790-000, Redenção, Ceará, Brasil. aialaamorim@unilab.edu.br

${ }^{6}$ Engenheira Agronôma, Doutora em Agronomia/ Irrigação e Drenagem, Instituto Federal de Educação, Ciência e Tecnologia do Ceará, Campus Sobral, Av. Dr. Guarani, n 317, Derby Clube, CEP 62.042-030, Sobral, Ceará, Brasil. liliancarv@ifce.edu.br
} 
Como os valores de $\mathrm{K}_{\mathrm{Y}}$ foram todos inferiores a 1, conclui-se que a cultura do girassol demonstrou uma baixa sensibilidade aos déficits hídricos aplicados na pesquisa.

Palavras-chave: agrometeorologia, balanço hídrico, evapotranspiração, Helianthus annuus L, $\mathrm{K}_{\mathrm{Y}}$.

\title{
WATER DEFICIT SENSITIVITY COEFFICIENTS FOR THE SUNFLOWER CULTURE IN THE CEARA (BRAZIL) SEMIARID CONDITIONS
}

\begin{abstract}
Aiming at determining the sunflower culture water stress $\left(K_{Y}\right)$ sensitivity coefficients in individual stages and at the entire crop cycle for the conditions of the Ceara semiarid, Brazil, a field experiment was conducted in the municipality of Pentecoste, Ceara (Brazil). The experimental design was that of randomized blocks with four replications and eight treatments, defined as a function of the time of induction of water deficit in the three sunflower phenological stages (vegetative, flowering and production formation), corresponding to the occurrence of water deficit in one, two or three stages. The water deficit irrigation dose was half the applied water dose corresponding to full irrigation. $\mathrm{K}_{\mathrm{Y}}$ values were obtained through the relationship between the fall of relative income and the relative evapotranspiration deficit, according to the method of Doorenbos and Kassam. The evapotranspirations (potential and culture) were calculated using the soil water balance method. The results showed that the water stress sensitivity varied in the following order: production formation, vegetative and flowering, for water deficit applied to only one developmental stage. For the deficit conditions in two stages, the coefficient $\mathrm{K}_{\mathrm{Y}}$ showed that the lack of water has the greatest impact on sunflower achene yield when it occurs in the stages vegetative and production formation. Since the values of $K_{Y}$ were all lower than 1 , it is concluded that the sunflower culture showed a low sensitivity to the water deficits studied in this research.
\end{abstract}

Keywords: agrometeorology, evapotranspiration, Helianthus annuиs L, water balance, $\mathrm{K}_{\mathrm{Y}}$.

\section{INTRODUÇÃO}

Com o aumento gradativo das áreas cultivadas e, a escassez de recursos hídricos torna-se necessário aprimorar o manejo da irrigação, visando uma melhor alocação do recurso água, do qual depende substancialmente a agricultura (LOPES et al., 2011; RODRIGUES et al., 2011).

Neste sentido, dentre as estratégias propostas para maximizar o uso eficiente da água na agricultura, destaca-se o emprego da estratégia de manejo da irrigação com déficit hídrico em estádios específicos de desenvolvimento da cultura que se mostram menos sensíveis, podendo-se, então, reduzir a lâmina de água aplicada, economizando água e acarretando mínimos efeitos sobre a produtividade, mantendo a mesma em um patamar satisfatório (MIORINI et al., 2011). Além disso, a água economizada pelo manejo da irrigação com déficit pode ser usada para irrigar outras áreas e/ou culturas. Com isso, os custos de oportunidade da água, podem ser 
largamente compensados pela perda econômica, devido à redução de rendimento consequente da restrição hídrica (ALI et al., 2007).

No entanto, para subsidiar a utilização da tecnologia do emprego da irrigação com déficit por parte dos produtores rurais e dada a complexidade entre as relações encontradas entre cultura, clima, água e solo no âmbito da análise dos efeitos da água sob os rendimentos da cultura, Doorenbos e Kassam (1994), no Boletim FAO 33, propuseram uma metodologia que objetiva solucionar esta problemática, mediante o emprego de um reduzido número de informações que, segundo os autores, consegue integrar de forma sintetizada os processos biológicos, fisiológicos, físicos e químicos que regem a relação entre os rendimentos da cultura e o uso da água.

O procedimento desenvolvido pelos referidos autores tem seu fundamento baseado no modelo de função de produção que foi desenvolvido por Stewart et al. (1977), o qual assume que a produtividade e a evapotranspiração são consideradas em termos relativos com respeito a seus valores máximos. Assim, o efeito da falta de água disponível no solo sobre o decréscimo da produtividade potencial, ocorrida durante o ciclo da cultura é quantificado mediante a determinação do coeficiente $\mathrm{K}_{\mathrm{Y}}$, que é considerado uma medida da sensibilidade da cultura ao déficit hídrico. No entanto, a principal modificação realizada por Doorenbos e Kassam (1994) em relação ao modelo original é o fato de que eles consideraram que um déficit hídrico de certa magnitude, expresso pela relação entre a evapotranspiração potencial e a evapotranspiração da cultura pode ocorrer tanto de forma contínua durante todo o período de crescimento da cultura, como durante qualquer um dos estádios fenológicos do crescimento. Daí, a importância do conhecimento dos coeficientes de sensibilidade ao déficit hídrico $\left(\mathrm{K}_{\mathrm{Y}}\right)$, nestes respectivos estádios, a fim de gerenciar a programação da irrigação deficitária.

A cultura do girassol (Helianthus annuus L.) vem ganhando importância no Brasil devido, principalmente, ao seu potencial de adaptação às mais diversas condições edafoclimáticas, e à sua aptidão para a produção de matéria prima para a indústria alimentícia e do biodiesel (GOMES et al., 2010). Porém, pouco se sabe sobre os efeitos do déficit hídrico durante os diferentes estádios fenológicos da cultura do girassol nas condições do semiárido cearense.

Muito embora a FAO apresente, no Boletim 33, os valores de $\mathrm{K}_{\mathrm{Y}}$ desta cultura obtidos através da avaliação de resultados de pesquisas, Kaboosi e Kaveh (2010) enfatizam que, os mesmos devem, preferencialmente, ser determinados para as condições locais nas quais serão eventualmente utilizados, devido, principalmente, à particularidade dos fatores ambientais que lhes são relacionados.

Valores de $K_{Y}$ obtidos a partir de experimentos com girassol, representando variedades altamente produtivas, bem adaptadas ao ambiente de crescimento e desenvolvimento sob alto nível de manejo de culturas, foram propostos por Doorenbos e Kassam (1994), com os seguintes valores: 0,25 para a fase de estabelecimento; 0,5 para o desenvolvimento vegetativo inicial; 1,0 para o florescimento; 0,8 para a frutificação e 0,95 para o déficit durante todo o período vegetativo.

Moutonnet (2002) traçou um comparativo entre duas séries de valores de $\mathrm{K}_{\mathrm{Y}}$ que foram obtidas a partir de um conjunto de dados reportados pela FAO e por uma Agência Internacional de Energia Atômica (AIEA). Dos resultados, o autor constatou que há uma ampla gama de variação para este coeficiente em termos de valores médios para as culturas em 
questão, 0,20 $<\mathrm{K}_{\mathrm{Y}}<1,15$ (FAO), e $0,08<\mathrm{K}_{\mathrm{Y}}<$ 1,75 (AIEA). Mediante a comparação dos valores, o autor evidenciou que entre os dois conjuntos de dados analisados não se averiguaram valores médios idênticos para $K_{Y} \mathrm{e}$ nem tão pouco faixas similares de variação, muito embora os valores tenham eventualmente mostrando tendências parecidas de comportamento. $\mathrm{O}$ que reforça a necessidade de estender e determinar esses dados de $K_{Y}$ para outras culturas e cultivares, e para outras condições de solo e clima, no intuito de alcançar e dar suporte a otimização matemática do planejamento e da execução do manejo de irrigação com déficit.

Diante do exposto, objetivou-se, com este trabalho, determinar os coeficientes de sensibilidade ao déficit hídrico $\left(\mathrm{K}_{\mathrm{Y}}\right)$ da cultura do girassol nos estádios isolados e no ciclo total da cultura para as condições do semiárido cearense, usando-se o modelo sugerido por Doorenbos e Kassam (1994).

\section{MATERIAL E MÉTODOS}

O experimento foi conduzido durante o período de setembro a dezembro de 2010 na Fazenda Experimental Vale do Curu (FEVC), situada na cidade de Pentecoste no Ceará e pertencente à Universidade Federal do Ceará (UFC). As coordenadas geográficas de referência do local são latitude 3\%49'25' S, longitude $39^{\circ} 20^{\prime} 20^{\prime \prime} \mathrm{W}$ e altitude média de 50 m. O clima é do tipo BSw'h', semiárido, quente, existindo uma pequena temporada úmida. Os dados meteorológicos relativos ao período experimental foram obtidos junto à estação agrometeorológica da Fazenda Experimental
Vale do Curu, situada nas imediações da área experimental (Tabela 1).

Tabela 1 - Médias mensais das variáveis climáticas registradas durante $\mathrm{o}$ período experimental. Pentecoste, Ceará, $2010^{1}$

\begin{tabular}{lccccc}
\hline \multicolumn{1}{c}{ Mês } & $\begin{array}{r}\text { Max. } \\
\left({ }^{\circ} \mathrm{C}\right)\end{array}$ & $\begin{array}{c}\text { Min. } \\
\left({ }^{\circ} \mathrm{C}\right)\end{array}$ & $\begin{array}{c}\text { Méd. } \\
\left({ }^{\circ} \mathrm{C}\right)\end{array}$ & $\begin{array}{c}\text { UR } \\
(\%)\end{array}$ & $\begin{array}{c}\text { Prec. } \\
(\mathrm{mm})\end{array}$ \\
\hline Setembro & 37,1 & 22,2 & 29,7 & 56 & 0 \\
Outubro & 38,3 & 22,8 & 30,5 & 46 & 0 \\
Novembro & 38,1 & 22,7 & 30,4 & 50 & 0 \\
Dezembro & 36,8 & 22,8 & 29,8 & 59 & 21,8 \\
\hline I: T Max. - Temperatura máxima do & ar; T Min. - \\
Temperatura mínima do ar; T Méd. - Temperatura média \\
do ar; UR - Umidade relativa do ar; Prec. - Precipitação \\
natural
\end{tabular}

O solo utilizado para o experimento foi classificado como Neossolo flúvico, textura franco-arenosa, baseado em EMBRAPA (2006). As análises químicas e textural foram realizadas pelo Laboratório de Solos e Água, do Departamento de Ciências do Solo do CCA/UFC (Tabela 2).

Tabela 2 - Caracterização química e granulométrica do solo, nas camadas $0-0,20$ e 0,20-0,40 m. Pentecoste, Ceará, 2010

\begin{tabular}{|c|c|c|c|c|c|c|c|c|c|c|c|}
\hline Camada & $\mathrm{pH}$ & $\mathrm{P}$ & K & $\mathrm{Na}$ & $\mathrm{Mg}$ & $\mathrm{Al}$ & $\mathrm{Ca}$ & M.O & Argila & Silte & Areia \\
\hline (iii) & (água) & \multicolumn{3}{|c|}{$\left(\mathrm{mg} \mathrm{dm}^{-3}\right)$} & \multicolumn{3}{|c|}{$\left(\mathrm{cmol}_{\mathrm{c}} \mathrm{dm}^{-3}\right)$} & \multicolumn{4}{|c|}{$\left(\mathrm{g} \mathrm{kg}^{-1}\right)$} \\
\hline $0-0,20$ & 7,2 & 78,0 & 515,0 & 73,0 & 3,7 & 0,0 & 4,8 & 18,9 & 146 & 224 & 693 \\
\hline $0,20-0,40$ & 7,2 & 56,0 & 246,0 & 70,0 & 4,0 & 0,0 & 4,5 & 12,0 & 172 & 231 & 679 \\
\hline
\end{tabular}

O preparo do solo constou de uma aração seguida de duas gradagens cruzadas. A adubação foi baseada na análise de solo e nas exigências nutricionais da cultura, conforme Aquino et al. (1993). 
A cultivar utilizada no trabalho foi a Multissol, no espaçamento entre as fileiras de $0,9 \mathrm{~m}$ e de $0,25 \mathrm{~m}$ entre as plantas nas fileiras. $\mathrm{O}$ desenvolvimento da cultura foi dividido em três estádios fenológicos, de acordo com recomendação de Schneider e Miller (1981): vegetativo, da semeadura até o estádio inicial de floração; floração do final do estádio anterior até a fase de floração final e formação da produção, do final do estádio anterior até a colheita.

O delineamento experimental utilizado foi o de blocos casualizados, em esquema de parcelas subdivididas no tempo (split-plot in time), com oito parcelas, três subparcelas e quatro blocos. Nas parcelas, com área de 16,2 $\mathrm{m}^{2}(2,7 \times 6 \mathrm{~m})$, foram avaliados os tratamentos que foram definidos em função da época de indução do déficit hídrico nos diferentes estádios fenológicos da cultura, correspondendo à ocorrência de déficit hídrico em um, dois ou três estádios, assim agrupados: T1: tratamento em que a cultura não sofreu déficit hídrico nos três estádios fenológicos (controle); T2: déficit hídrico no estádio de formação da produção; T3: déficit hídrico no estádio de floração; T4: déficit hídrico nos estádios de floração e formação da produção; T5: déficit hídrico no estádio vegetativo; T6: déficit hídrico nos estádios vegetativo e formação da produção; T7: déficit hídrico nos estádios vegetativo e floração; T8: déficit hídrico nos três estádios fenológicos.

A área total ocupada pelo experimento foi de $864 \mathrm{~m}^{2}(28,8 \times 30 \mathrm{~m})$, composta por 128 linhas de plantio. Cada linha útil de plantas ocupou a área de $5,4 \mathrm{~m}^{2}$, contendo vinte e quatro plantas cada. A cultura foi irrigada pelo método localizado, com o sistema do tipo gotejamento sobre linha. Os gotejadores eram do tipo autocompensantes, com vazão média de 3,75 L $\mathrm{h}^{-1}$ a uma pressão de serviço de $150 \mathrm{kPa}$, e foram espaçados de $0,5 \mathrm{~m}$ na linha com um gotejador por duas plantas. No início de cada linha lateral de irrigação foi instalado um registro, a fim de controlar a quantidade de água aplicada nas unidades experimentais.

Após a instalação do sistema de irrigação, procedeu-se a avaliação da uniformidade de distribuição de água no sistema, por meio da metodologia proposta por Keller e Karmeli, modificada por Deniculli et al. (1980), que consiste na coleta da vazão dos gotejadores em oito pontos ao longo da linha lateral e em quatro linhas laterais, ao longo da linha de derivação.

Após a semeadura, a área experimental foi irrigada diariamente com uma dose de irrigação equivalente a $100 \%$ da evapotranspiração de referência estimada através da evaporação medida em um tanque classe A, a fim de garantir a uniformidade do estande até o início da diferenciação dos tratamentos, que se deu aos 21 dias após a semeadura (DAS). As unidades experimentais submetidas ao déficit hídrico ao longo do ciclo da cultura receberam $50 \%$ da dose de água aplicada no Tratamento 1 (controle). Após o início da diferenciação dos tratamentos, a quantidade de água aplicada em cada tratamento passou a ser reposta a cada dois dias e as quantidades aplicadas continuaram tendo por base a evapotranspiração de referência ETo, estimada pelo tanque classe A.

A evapotranspiração de referência (ETo) foi estimada através da equação 1 (BERNARDO; SOARES; MANTOVANI, 2006):

$$
E T o=E C A . K t
$$

em que, ETo é a evapotranspiração de referência estimada através do tanque classe A (mm); ECA é a evaporação medida através do tanque Classe 
A (mm); Kt é o coeficiente de ajuste do tanque (adimensional).

$\mathrm{O}$ coeficiente de ajuste do tanque $(\mathrm{Kt})$ foi calculado através da equação 2 proposta por Snyder (1992):

$$
K t=0,482+0,24 \ln (F)-0,00037 U+0,0045 U R
$$

em que, Kt é o coeficiente de ajuste do tanque (adimensional); F é a menor distância do centro do tanque ao limite da bordadura (m); U é avelocidade do vento $\left(\mathrm{km} \mathrm{dia}{ }^{-1}\right)$; UR é a umidade relativa do ar (\%).

A irrigação total necessária foi calculada pela equação 3 proposta por Bernardo, Soares e Mantovani(2006):

$$
I T N=\frac{L I \cdot P A M}{C U D}
$$

em que, ITN é a irrigação total necessária (mm); LI é a lâmina de irrigação, referente à evapotranspiração de referência (ETo) (mm); PAM é a percentagem de área molhada (Valor adotado 0,40); CUD é o coeficiente de uniformidade de distribuição de água do sistema de irrigação (Obtido em avaliação de campo, CUD $=0,90$ ).

Já o tempo de irrigação foi calculado a partir da equação 4:

$$
T_{I}=\frac{I T N \cdot A_{P}}{N e f \cdot q_{g}}
$$

em que, $\mathrm{T}_{\mathrm{I}}$ é o tempo de irrigação (h); ITN é a irrigação total necessária $(\mathrm{mm}) ; A_{P}$ é a área da faixa de plantio $\left(\mathrm{m}^{2}\right) ;\left(\mathrm{Ap}=6 \times 0,9=5,4 \mathrm{~m}^{2}\right)$; Nef é o número de emissores na faixa de plantio $(\mathrm{Nef}=12) ; \mathrm{q}_{\mathrm{g}}$ é a vazão do gotejador $\left(\mathrm{L} \mathrm{h}^{-1}\right)\left(\mathrm{q}_{\mathrm{g}}\right.$ $=3,75 \mathrm{~L} \mathrm{~h}^{-1}$ ).

Durante o período de condução do experimento, sempre que necessário, procederam-se tratos culturais e controle fitossanitário, seguindo recomendações de Leite et al. (2005). Desta forma, foram realizadas duas capinas com auxílio de enxadas manuais, aos 21 e aos 42 dias após a semeadura - DAS com o objetivo de eliminar as plantas infestantes e evitar a concorrência das mesmas com a cultura por água e nutrientes. Foram procedidos os tratamentos fitossanitários necessários, mediante a realização de três pulverizações com os inseticidas ORTHENE 750 BR e VERTIMEC $^{\circledR} 18$ EC, aos 13, 21 e 41 DAS.

A estimativa do potencial de produção de aquênios em $\mathrm{kg} \mathrm{ha}^{-1}$ foi realizada por meio da pesagem da produção de aquênios beneficiados de dez plantas que se encontravam inseridas na área útil do experimento por cada parcela, considerando a área ocupada por cada planta e o número total de plantas utilizado.

Para o cálculo dos coeficientes de sensibilidade ao déficit hídrico da cultura do girassol $\left(\mathrm{K}_{\mathrm{Y}}\right)$ foi utilizada a equação, descrita por Doorenbos e Kassam (1994), que quantifica a relação entre a redução do rendimento relativo e o déficit de evapotranspiração:

$$
K_{Y}=\frac{\left[1-\left(Y_{R} Y_{M}^{-1}\right)\right]}{\left[1-\left(E T c E T p c^{-1}\right)\right]}
$$

em que, $K_{Y}$ é o coeficiente de sensibilidade ao déficit hídrico da cultura do girassol; $Y_{R}$ é o potencial de produção de aquênios dos tratamentos submetidos ao déficit hídrico (T2, T3, T4, T5, T6, T7 e T8) $\left(\mathrm{kg} \mathrm{ha}^{-1}\right)$; $\mathrm{Y}_{\mathrm{M}}$ é o potencial de produção de aquênios do tratamento que não sofreu déficit hídrico (T1) $\left(\mathrm{kg} \mathrm{ha}^{-1}\right)$; ETc é a evapotranspiração da cultura acumulada no período de déficit hídrico ( $\mathrm{mm}$ período $\left.^{-1}\right)$; ETPc é a evapotranspiração potencial da cultura acumulada no tratamento 
que não sofreu déficit hídrico, no mesmo período da ETc acumulada nos tratamentos sob déficit hídrico ( $\mathrm{mm}_{\text {período }}{ }^{-1}$ ).

Para a estimativa da evapotranspiração (potencial da cultura e da cultura), empregou-se o método do balanço hídrico no solo com uma cultura agrícola, que tem fundamento básico na lei da conservação das massas, e é definido por Libardi (2005), como a contabilização das entradas e saídas de água num dado volume de controle de solo, durante certo período de tempo. Reichardt e Timm (2004) descrevem a equação que define o balanço hídrico no solo com uma cultura agrícola de uma maneira simplificada, conforme:

$$
P+I-E T \pm Q_{Z}+E S= \pm \Delta h
$$

em que, $\mathrm{P}$ é a precipitação natural (mm); I é a irrigação (mm); ET é a evapotranspiração potencial da cultura $(\mathrm{mm}) ; \mathrm{Q}_{\mathrm{z}}$ é a percolação profunda, quando é negativo, ou a ascensão capilar, quando positivo $(\mathrm{mm})$; ES é o escoamento superficial, que entra (+) ou sai (-) (mm); $\Delta$ h é a variação da armazenagem da água do solo na camada de profundidade de 0 a $\mathrm{z}$ para o intervalo de tempo considerado do balanço.

As evapotranspirações foram, então, calculadas para o período de 21 e 103 DAS. Como não houve registros de precipitação natural para os períodos nos quais o balanço hídrico foi realizado, este componente foi desprezado. As doses de irrigação aplicadas foram definidas em função dos respectivos tratamentos.

Para a estimativa da percolação profunda ou ascensão capilar, e para o cálculo da variação da armazenagem de água foram instalados três tensiômetros de punção da marca SONDATERRA $^{\circledR}$ a metade da extensão da linha útil de plantas de duas das repetições (blocos), entre duas plantas úteis nas profundidades de 0,$10 ; 0,30$ e $0,50 \mathrm{~m}$.

De posse dos valores dos potenciais matriciais e totais e das respectivas umidades volumétricas calculou-se a percolação profunda ou a ascensão capilar da água do solo para a profundidade $\mathrm{z}=0,40 \mathrm{~m}$, através da equação proposta por Buckingham-Darcy, escrita de uma maneira simplificada por Reichardt e Timm (2004):

$$
Q_{Z}=-K(\theta) \cdot \frac{\Delta \Psi_{t}}{\Delta z}
$$

em que, $\mathrm{Q}_{z}$ é a percolação ou ascensão capilar; $K(\theta)$ é a condutividade hidráulica em função da umidade do solo; $\frac{\Delta \Psi_{t}}{\Delta z}$ é o gradiente do potencial total da água no solo na profundidade $\mathrm{Z}$.

Escrevendo a equação acima, para a direção vertical, na profundidade $\mathrm{z}=0,40 \mathrm{~m}$, tem-se:

$$
Q_{z}=-K(\theta)_{40}\left\{\frac{\Psi_{t}^{30}-\Psi_{t}^{50}}{20}\right\}_{40}
$$

em que, $K(\theta)_{40}$ é a condutividade hidráulica do solo em função da umidade do solo $\theta$ na profundidade $0,40 \mathrm{~m}\left(\mathrm{~mm} \mathrm{dia}^{-1}\right) ;\left\{\frac{\psi_{t}^{30}-\psi_{t}^{50}}{20}\right\}_{40}$ é o gradiente de potencial total da água do solo para $\mathrm{z}=0,40 \mathrm{~m}$ (m c a); $\psi_{t}^{30}$ é o potencial total da água do solo a $0,30 \mathrm{~m}$ (m c a); $\psi_{t}^{50}$ é o potencial total da água do solo a $0,50 \mathrm{~m}(\mathrm{~m} \mathrm{c}$ a).

Os valores de $\mathrm{K}(\theta)_{40}$ foram determinados a partir da equação que define a condutividade 
hidráulica do solo da área experimental a 0,40 m, que foi obtida por Silva e Bezerra (2009), através da aplicação do método de Hillel et al. (1972), modificado por Saunders (1978), apresentada a seguir.

$$
K(\theta)_{40}=7.10^{-9} e^{45,942 \theta}
$$

em que, $K(\theta)_{40}$ é a condutividade hidráulica do solo na profundidade $0,40 \mathrm{~m}\left(\mathrm{~mm} \mathrm{dia}^{-1}\right) ; \theta$ é a umidade do solo $\left(\mathrm{m}^{3} \mathrm{~m}^{-3}\right)$.

A variação da armazenagem da água do solo para os intervalos de tempo considerados no balanço, para a profundidade estudada foi obtida pela equação desenvolvida por Reichardt e Timm (2004):

$$
\Delta h=\left(\bar{\theta}_{1}-\bar{\theta}_{2}\right) z
$$

em que, $\bar{\theta}_{1}$ é a umidade média do perfil até $\mathrm{z}=$ $0,40 \mathrm{~m}$, no dia da irrigação $\left(\mathrm{m}^{3} \mathrm{~m}^{-3}\right) ; \bar{\theta}_{2}$ é a umidade média do perfil até $\mathrm{z}=0,40 \mathrm{~m}$, no dia da irrigação anterior $\left(\mathrm{cm}^{3} \mathrm{~cm}^{-3}\right) ; \quad z$ é a profundidade adotada para o balanço $(\mathrm{z}=$ 0,40 m).

Nas condições em que o presente trabalho foi conduzido, o componente escoamento superficial (ES) não foi considerado, visto que a área onde o experimento foi conduzido pode ser considerada plana.

A componente evapotranspiração é a incógnita da equação do balanço hídrico. Explicitando a equação (2), tem-se:

$$
E T=I \pm Q_{z}-( \pm \Delta h)
$$

Para as condições nas quais a pesquisa foi conduzida, a componente evapotranspiração (ET) é conceituada como evapotranspiração potencial da cultura (ETpc), aquela obtida em T1, e evapotranspiração da cultura (ETc) aquela obtida nos tratamentos submetidos ao déficit hídrico nas diversas fases fenológicas da cultura.

\section{RESULTADOS E DISCUSSÃO}

Na Tabela 4 são apresentados os valores médios dos parâmetros que compõem os cálculos dos coeficientes de sensibilidade ao déficit hídrico $\left(\mathrm{K}_{\mathrm{Y}}\right)$, levando-se em consideração os rendimentos de aquênios e os respectivos resultados para cada tratamento no qual a cultura do girassol foi submetida ao longo de seus estádios fenológicos.

Tabela 4 - Parâmetros componentes dos cálculos dos coeficientes de sensibilidade ao déficit hídrico $\left(\mathrm{K}_{\mathrm{Y}}\right)$ da cultura do girassol nos estádios isolados e no ciclo total da cultura para

\begin{tabular}{|c|c|c|c|c|c|c|c|}
\hline \multirow{2}{*}{ Parâmetros } & \multicolumn{7}{|c|}{ Tratamentos } \\
\hline & $\mathrm{T} 2$ & $\mathrm{~T} 3$ & $\mathrm{~T} 4$ & $\mathrm{~T} 5$ & T6 & $\mathrm{T} 7$ & $\mathrm{~T} 8$ \\
\hline YR $\left(\mathrm{kg} \mathrm{ha}^{-1}\right)$ & $3.906,96$ & $4.420,31$ & $3.537,71$ & $4.210,26$ & $3.073,35$ & $3.725,46$ & $2.877,39$ \\
\hline YM $\left(\mathrm{kg} \mathrm{ha}^{-1}\right)$ & $4.537,90$ & $4.537,90$ & $4.537,90$ & $4.537,90$ & $4.537,90$ & $4.537,90$ & $4.537,90$ \\
\hline $\mathrm{Y}_{\mathrm{R}} \mathrm{YM}^{-1}$ & 0,8609 & 0,974 & 0,7795 & 0,9277 & 0,6772 & 0,8209 & 0,634 \\
\hline$\left[1-\left(\mathrm{Y}_{\mathrm{R}} \mathrm{YM}^{-1}\right)\right]$ & 0,139 & 0,0259 & 0,2204 & 0,0722 & 0,3227 & 0,179 & 0,3659 \\
\hline ETc (mm período ${ }^{-1}$ ) & 42,42 & 22,73 & 65,15 & 48,23 & 90,65 & 70,96 & 113,38 \\
\hline ETpc $\left(\mathrm{mm}\right.$ período $\left.{ }^{-1}\right)$ & 112,05 & 84,51 & 196,56 & 124,44 & 236,49 & 208,95 & 321,00 \\
\hline $\mathrm{ETc}_{\mathrm{ETPc}}{ }^{-1}$ & 0,3785 & 0,269 & 0,3314 & 0,3876 & 0,3833 & 0,3396 & 0,3532 \\
\hline$\left[1-\left(\mathrm{ETc}^{\mathrm{ETpc}}{ }^{-1}\right)\right]$ & 0,6215 & 0,731 & 0,6686 & 0,6124 & 0,6167 & 0,6604 & 0,6468 \\
\hline KY & 0,22 & 0,04 & 0,33 & 0,12 & 0,52 & 0,27 & 0,57 \\
\hline \multicolumn{8}{|c|}{$\begin{array}{l}{ }^{2} \mathrm{Y}_{\mathrm{R}} \text { - Potencial de produção de aquênios dos tratamentos } \\
\text { submetidos ao déficit hídrico (T2, T3, T4, T5, T6 e T7); } \\
\mathrm{Y}_{\mathrm{M}} \text { - Potencial de produção de aquênios do tratamento } \\
\text { que não sofreu déficit hídrico; } \mathrm{Y}_{\mathrm{R}} \mathrm{Y}_{\mathrm{M}}{ }^{-1}-\mathrm{Razão} \text { entre os } \\
\left.\text { potenciais de produção de aquênios; [1 - }\left(\mathrm{Y}_{\mathrm{a}} \mathrm{Y}_{\mathrm{m}}{ }^{-1}\right)\right] \text { - } \\
\text { Déficit de produtividade; ETc - Valores da }\end{array}$} \\
\hline
\end{tabular}
as condições do semiárido cearense. Pentecoste, Ceará, $2010^{2}$ 
evapotranspiração da cultura acumulada no período de déficit hídrico; ETpc - Valores da evapotranspiração potencial da cultura acumulada no tratamento 1 , no mesmo período da ETc acumulada nos tratamentos sob déficit hídrico; (ETc ETPc $\left.{ }^{-1}\right)$ - Razão entre as evapotranspirações da cultura e a potencial; [1 - (ETc ETpc $\left.\left.{ }^{-1}\right)\right]$ - Déficit de evapotranspiração; $K_{Y}$ Coeficientes de sensibilidade ao déficit hídrico da cultura do girassol.

A amplitude de variação observada de $\mathrm{K}_{\mathrm{Y}}$ considerando os rendimentos de aquênios foi de 0,04 até 0,57 . Analisando os valores médios de $\mathrm{K}_{\mathrm{Y}}$ dos tratamentos T2, T3 e T5, que foram submetidos a déficit hídrico em apenas um estádio fenológico, observa-se que a redução relativa do rendimento de aquênios da cultura do girassol foi mais acentuada no estádio de formação da produção (T2) com $\mathrm{K}_{\mathrm{Y}}=0,22$. De acordo com Doorenbos e Kassam (1994), em condições de irrigação deficitária, a cultura sofrerá maior efeito do déficit sob a perda de rendimento, quanto maior for o valor de $\mathrm{K}_{\mathrm{Y}}$ apresentado para cada respectivo estádio fenológico (Tabela 4).

Verifica-se ainda na Tabela 4 que dentre os tratamentos T3 e T5, nos quais os déficits de irrigação aconteceram nos estádios de floração e vegetativo, respectivamente, que a restrição de água teve maior impacto sobre o rendimento de aquênios quando ocorreu no estádio vegetativo $\left(K_{Y}=0,12\right)$ e exerceu o mínimo efeito sobre o potencial de produção de aquênios da cultura, quando incidiu isoladamente durante o estádio de floração, apresentando valores praticamente nulos, com um valor médio de $\mathrm{K}_{\mathrm{Y}}$ de apenas 0,04. Como o início da imposição do déficit hídrico na presente pesquisa se deu apenas aos 21 dias após a semeadura, não se pode afirmar de fato qual seria o real efeito que o déficit hídrico exerceria sobre o valor de $\mathrm{K}_{\mathrm{Y}}$, caso o mesmo fosse aplicado a partir da fase de germinação.
Os resultados obtidos neste trabalho contradizem, de certa maneira, os relatos de Doorenbos e Kassam (1994), ao informarem que, de uma maneira geral, ao se analisar as consequências do déficit hídrico em estádios fenológicos específicos das culturas agrícolas, esperam-se um menor decréscimo no rendimento relativo para o período correspondente à fase vegetativa e de formação da produção, e em contrapartida, as maiores reduções na produtividade devem ser relativamente superiores para o caso de escassez hídrica no estádio de floração.

Tal comportamento pode ser explicado levando-se em conta a menor duração cronológica do estádio de floração (16 dias), quando equiparado ao demais (vegetativo: 52 dias; formação da produção: 42 dias) dentro da escala de identificação das fases de desenvolvimento proposta por Schneider e Miller (1981), que foi adotada na presente pesquisa como critério de separação temporal dos estádios fenológicos, fato que resultou em um período de exposição ao déficit hídrico relativamente curto para o estádio de floração, quando equiparado aos demais nas condições nas quais a pesquisa foi conduzida. O que é condizente com informações de Leite et al. (2005), ao mencionarem que a perda de produtividade, em função da exposição da cultura ao déficit hídrico na cultura do girassol varia principalmente em função do estádio fenológico das plantas e do tempo de exposição das mesmas ao déficit hídrico. Tais valores, quando comparados com os citados por Doorenbos e Kassam (1994), apresentaram consideráveis diferenças, uma vez que estes autores obtiveram na floração $\mathrm{K}_{\mathrm{Y}}=1$, enquanto se obteve $K_{Y}=0,04$ no presente estudo. Os outros dois estádios também apresentaram discrepâncias: formação da produção $\left(K_{Y}=0,80\right.$ 
para Doorenbos e Kassam, contra $\mathrm{K}_{\mathrm{Y}}=0,22$ ) e vegetativo $\left(\mathrm{K}_{\mathrm{Y}}=0,62\right.$ para Doorenbos e Kassam, contra $\mathrm{K}_{\mathrm{Y}}=0$, 12, para o presente estudo).

Cordeiro et al. (1998) também constataram diferenças entre os valores que foram determinados para a cultura do feijão caupi nas condições do litoral cearense e aqueles que são listados por Doorenbos e Kassam (1994) e sugerem que estas altercações podem estar relacionadas às próprias condições edafoclimáticas locais, bem como a adequada adaptação da cultura as condições semiáridas, que é refletida na inferioridade dos valores de $\mathrm{K}_{\mathrm{Y}}$ na presente condição, em comparação com os que são citados pela FAO. Todavia, deve-se considerar que segundo estes autores, as divergências existentes entre os valores de $\mathrm{K}_{\mathrm{Y}}$ podem resultar dos próprios erros experimentais, e das variações climáticas e de solos, que de forma conjugada definem o nível de evapotranspiração de uma determinada cultura em certa condição de suprimento hídrico. Os referidos autores ainda ressaltam que a literatura não dispõe de valores de $K_{Y}$ que possam ser considerados como padrão de referência para fins comparativos, mas apenas se julga que a confiabilidade dos valores de $\mathrm{K}_{\mathrm{Y}}$ reportados pela FAO, é similar aquela que é resultante da análise dos resultados experimentais conduzidos em condições de campo.

De forma semelhante, Freitas et al. (1999), também evidenciaram desigualdades entre os valores de $\mathrm{K}_{\mathrm{Y}}$ encontrada nos estádios de desenvolvimento da melancia no município de Canindé-CE, em relação aos valores apresentado pela FAO e justificaram que estas heterogeneidades são decorrentes do genótipo e da própria separação temporal das fases fenológicas da cultura utilizados em sua investigação, o que reforça os resultados alcançados, tendo em vista que a escala fenológica proposta pela FAO, diverge daquela adotada na presente pesquisa, pois Doorenboos e Kassam (1994) dividiram a temporada total de crescimento do girassol em quatro estádios (vegetativo inicial e final, floração e formação da colheita), enquanto neste ensaio, apenas em três.

Estes resultados estão, portanto, em consonância com relatos de Kaboosi e Kaveh (2010), que enfatizam que ao empregar os valores dos coeficientes de sensibilidade aos déficits hídricos (KY) estimados para outros locais, é necessário atentar tanto para o número, bem como a própria definição dos estádios de crescimento da cultura em questão, uma vez que, as aplicações dos coeficientes $K_{Y}$ nas estimativas dos rendimentos relativos podem resultar em erros, quando os mesmos são utilizados para outros locais, bem como em situações nas quais os estádios de desenvolvimento da cultura são subdivididos em diferentes números de fases, acarretando assim modificação na duração das mesmas ao longo da estação de cultivo.

Dentre os valores dos coeficientes de sensibilidade $\mathrm{K}_{\mathrm{Y}}$ obtidos nos tratamentos sujeitos ao déficit hídrico em mais de um estádio fenológico (T4, T6, T7 e T8), constatouse que o tratamento $\mathrm{T} 8$, o qual foi submetido à deficiência hídrica durante todo o ciclo da cultura conferiu o maior valor de $\mathrm{K}_{\mathrm{Y}}(0,57)$. Nos tratamentos cultivados com déficit em dois estádios fenológicos (T4, T6, T7), os valores de $\mathrm{K}_{\mathrm{Y}}$ foram de 0,33; 0,52 e 0,27, respectivamente, sendo que o maior dos valores deu-se no tratamento T6, caracterizado por estar vulnerável a implicação dos efeitos do déficit hídrico nos estádios vegetativo e de formação da produção, o que era esperado, tendo em vista que este referido tratamento praticamente 
contempla todo o ciclo cultural, exceto apenas o estádio de menor duração (floração). Assim, presume-se que o impacto do déficit hídrico nesses estádios é maior que nos estádios de floração e de formação da produção $\left(K_{Y}=\right.$ $0,33)$, ou vegetativo e floração $\left(K_{Y}=0,27\right)$.

De acordo com Doorenbos e Kassam (1994), quando os valores de $\mathrm{K}_{\mathrm{Y}}$ são inferiores a 1 , isto denota que a cultura ou o estádio fenológico considerado, pode ser considerado resistente à deficiência hídrica, de tal forma que os decréscimos dos rendimentos são relativamente inferiores à restrição relativa de água na qual a cultura foi submetida. Em contrapartida, quando os valores de $K_{Y}$ são superiores a 1, infere-se que a cultura ou o estádio fenológico em análise se demonstra vulnerável aos efeitos da escassez hídrica, uma vez que as reduções de rendimentos se mostram relativamente superiores à restrição relativa de água na qual a cultura foi submetida. Finalmente, quando os valores de $\mathrm{K}_{\mathrm{Y}}$ se igualam a 1, considera-se que a situação é intermediária, pois os decréscimos dos rendimentos são relativamente equivalentes às restrições relativas de água nas quais a cultura foi exposta durante a temporada total, ou estádio específico de desenvolvimento.

Dentro da escala proposta pelos referidos autores, no que se relaciona a sensibilidade ao déficit hídrico às culturas ou os estádios fenológicos podem ainda ser classificadas função dos valores de $\mathrm{K}_{\mathrm{Y}}$ apresentados em de baixa sensibilidade $\left(\mathrm{K}_{\mathrm{Y}}<0,85\right)$; de baixa/média sensibilidade $\left(0,85<\mathrm{K}_{Y}<1,00\right)$; de média/alta sensibilidade $\left(1,00<K_{Y}<1,15\right)$ e de alta sensibilidade $\left(K_{Y}>1,15\right)$. Desta forma, os resultados da presente experimentação apontam que a cultura do girassol demonstrou uma baixa sensibilidade ao déficit hídrico adotado, no que se relaciona ao potencial de produção de aquênios, independente do estádio de desenvolvimento, considerando todas as condições nas quais o ensaio foi conduzido.

Assim, podem-se fazer restrições no suprimento hídrico da cultura do girassol de forma estratégica com o nível de déficit hídrico de $50 \%$ da ETo em todos os estádios fenológicos da cultura, considerando as premissas do modelo proposta pela FAO, tendo em vista que todos os valores de $K_{Y}$ foram inferiores a 1 .

Erdem e Delibas (2003) também determinaram os coeficientes de sensibilidade ao déficit hídrico $\left(\mathrm{K}_{\mathrm{Y}}\right)$ nas diferentes fases de desenvolvimento da cultura do girassol em condições semiáridas na Turquia e averiguaram que todos os valores de $\mathrm{K}_{\mathrm{Y}}$ mensurados foram inferiores a 1, indicando também baixa sensibilidade ao déficit hídrico, sendo os valores de 0,28 para o estádio vegetativo, 0,67 para o estádio de floração e 0,40 para a fase de formação da produção. Constata-se, portanto, que apenas os resultados de $\mathrm{K}_{\mathrm{Y}}$ mensurados durante o estádio vegetativo são semelhantes aos obtidos na presente pesquisa. Estes resultados ainda divergem das conclusões dos referidos autores que apontam o período de floração, como o mais sensível ao déficit hídrico dentre os outros períodos analisados.

Demir et al. (2006) ao avaliar os coeficientes de sensibilidade ao déficit hídrico $\left(\mathrm{K}_{\mathrm{Y}}\right)$ do girassol submetido à irrigação plena e a treze distintas estratégias de manejo da irrigação com déficit na cultura do girassol em uma condição subúmida na Turquia também verificaram que independente do estádio de desenvolvimento, todos os valores de $K_{Y}$ se mostraram inferiores a 1 , e ao contrário do que se constatou no presente trabalho, em alguns estádios do desenvolvimento nos quais o déficit foi aplicado individualmente, foram encontrados 
valores de $\mathrm{K}_{\mathrm{Y}}$ superiores aqueles computados quando se aplicou o déficit durante toda estação de cultivo, de tal forma que os valores foram de 0,$91 ; 0,90 ; 0,89$ e 0,83 para a fase vegetativa, floração, formação da produção e para todo o ciclo, respectivamente.

De forma semelhante, os referidos autores também denotaram diferenças entre os valores de $K_{Y}$ que foram mensurados e aqueles descritos pela FAO e atribuíram também esta discrepância as diferenças de separação dos estádios fenológicos e as modificações que a cultura pode apresentar nas respostas da irrigação dependendo do tipo de solo e das circunstâncias climáticas.

Estes resultados são divergentes dos obtidos por Sezen et al. (2011), quando constataram que a cultura do girassol demonstrou ser altamente sensível ao déficit hídrico por demonstrar valores de $\mathrm{K}_{\mathrm{Y}}$ superiores a 1 em um estudo que comparou durante dois ciclos os efeitos de diferentes regimes de irrigação por aspersão e gotejamento na região mediterrânea da Turquia. Estes autores registraram que os valores de $K_{Y}$ para a produtividade de aquênios generalizada para todo ciclo total foi de 1,24 e 0,86 para a aspersão e 1,19 e 1,06 para o sistema de gotejamento em 2006 e 2007, respectivamente e os valores de $\mathrm{K}_{\mathrm{Y}}$ mensurados para a produtividade de óleo durante o ciclo total foi de 1,08 e 1,49 para a aspersão e 1,36 e 1,25 para o gotejamento em ambos os períodos de experimentação, respectivamente.

\section{CONCLUSÕES}

A sensibilidade ao déficit hídrico mensurada através do coeficiente $\mathrm{K}_{\mathrm{Y}}$ em cada estádio variou na seguinte ordem decrescente: formação da produção, vegetativo e floração, para déficit aplicado em apenas um estádio fenológico. Para as condições de déficit em dois estádios, o coeficiente $K_{Y}$ indicou que a insuficiência de água tem maior impacto sobre o rendimento de aquênios do girassol quando ocorre simultaneamente nos estádios vegetativo e de formação da produção.

Os valores de $\mathrm{K}_{\mathrm{Y}}$ obtidos nos tratamentos estudados foram todos inferiores a 1 , indicando a baixa sensibilidade da cultura do girassol aos déficits hídricos aplicados na pesquisa.

A adoção da dose de irrigação equivalente a $50 \%$ da evapotranspiração de referência durante todo o ciclo do girassol permitiu aumentar a eficiência de uso da água de irrigação na produção de aquênios, uma vez que os decréscimos dos rendimentos foram relativamente inferiores à restrição relativa de água na qual a cultura foi submetida $\left(\mathrm{K}_{\mathrm{Y}}<1\right)$.

Os valores de $\mathrm{K}_{\mathrm{Y}}$ obtidos no presente experimento divergem dos valores apresentados na bibliografia, o que ressalta a necessidade do cálculo deste coeficiente para as especificidades de clima, solo, genótipo e divisão fenológica.

\section{REFERÊNCIAS}

ALI, M.H.; HOQUE, M.R.; HASSAN, A.A.; KHAIR, A. Effects of deficit irrigation on yield, water productivity, and economic returns of wheat. Agricultural Water Management, Amsterdam, v.92, n.3, p.151-161, 2007.

AQUINO, A. B.; AQUINO, B. F.; HERNANDEZ, F. F. F.; HOLANDA, F. J. M.; FREIRE, J. M.; CRISOSTOMO, L. A.; 
COSTA, R. I.; UCHÔA, S. C. P.; FERNANDES, V. L. B. Recomendações de adubação e calagem para o Estado do Ceará. 1 ed. Fortaleza: UFC, 1993. 247p.

BERNARDO, S.; SOARES, A. A.; MANTOVANI, E. C. Manual de Irrigação. 8. ed. Viçosa: Editora UFV, 2006. 625 p.

CORDEIRO, L. G.; BEZERRA, F. M. L.; SANTOS, J. J. A. dos; MIRANDA, E. P. de. Fator de sensibilidade ao déficit hídrico da cultura do feijão caupi (Vigna unguiculata (L.) Walp.). Revista Brasileira de Engenharia Agrícola e Ambiental, Campina Grande, v.2, n.2, p.153-157, 1998.

DEMIR, A.; GÖKSOY, A. T.; BÜYÜKCANGAZ, H.; TURAN, Z.; KÖKSAL; E. S. Deficit irrigation of sunflower (Helianthus annuus L.) in a sub-humid climate. Irrigation Science, v. 24, p. 279-289, 2006.

DENÍCULI, W.; BERNARDO, S.; THIÉBAUT, J.T.L.; SEDIYAMA, G.C. Uniformidade de distribuição de água, em condições de campo num sistema de irrigação por gotejamento. Revista Ceres, Viçosa, v.27, n.150, p155-162, 1980.

DOORENBOS, J.; KASSAM, A. H. Efeito da água no rendimento das culturas. Campina Grande: UFPB, 1994. 306p. Estudos da FAO: Irrigação e Drenagem, 33.

EMBRAPA - EMPRESA BRASILEIRA DE PESQUISA AGROPECUÁRIA. Centro Nacional de Pesquisa de Solos. Sistema Brasileiro de Classificação de Solos. 1 ed. Rio de Janeiro: Embrapa Solos, 2006. 412 p.

ERDEM, T.; DELIBAS, L. Yield response of sunflower to water stress under tekirdag conditions. Helia, v. 26, n. 38, p. 149-158, 2003.

FREITAS, A. A. de; BEZERRA, F. M. L.; FONTENELE, F. das C. B. Determinação da evapotranspiração máxima e real e do fator de sensibilidade ao déficit hídrico da melancia em Canindé, CE. Revista Brasileira de Engenharia Agrícola e Ambiental, Campina Grande, v.3, n.3, p.298-303, 1999.

GOMES, E. P.; ÁVILA, M. R.; RICKLI, M. E.; PETRI, F.; FEDRI, G. Desenvolvimento e produtividade do girassol sob lâminas de irrigação em semeadura direta na região do Arenito Caiuá, estado do Paraná. Irriga, Botucatu, v. 15, n. 4, p. 373-385, outubrodezembro 2010.

HILLEL, D.; KRENTOS, V.D.; STYLIANOV, Y. Procedure and test of an internal drainage method for measuring soil hydraulic characteristics in situ. Soil Science, Baltimore, v.114, p. 395-400, 1972.

KABOOSI, K.; KAVEH, F. Sensitivity analysis of Doorenbos and Kassam (1979) crop water production function. African Journal of Agricultural Research, v. 5, n. 17, p. 23992417, september, 2010.

LEITE, R.M.V.B.C.; BRIGHENTI, A.M.; CASTRO, C. de. (Ed.). Girassol no Brasil. Londrina: Embrapa Soja, 2005. 613p.

LIBARDI, P.L. Dinâmica da água no solo. São Paulo: EDUSP, 335p., 2005.

LOPES, F. B.; SOUZA, F. de; ANDRADE, E. M. de; MEIRELES, A. C. M.; CAITANO, R. F. Determinação do padrão do manejo da irrigação praticada no perímetro irrigado Baixo Acaraú, Ceará, via análise multivariada. Irriga, Botucatu, v. 16, n. 3, p. 301-316, julhosetembro, 2011.

MARIN, F. R.; PANDORFI, H.; SENTELHAS, P. C.; CAMARGO, M. B. P. de; HERNANDEZ, F. B. T. Perda de produtividade potencial da cultura do sorgo no Estado de São Paulo. Bragantia, Campinas, v.65, n.1, p. 157162, 2006.

MIORINI, T. J. J.; SAAD, J. C. C.; MENEGALE, M. L. Supressão de água em diferentes fases fenológicas do feijoeiro 
(Phaseolus vulgaris L.). Irriga, Botucatu, v. 16, n. 4, p. 360-368, outubro-dezembro, 2011.

MOUTONNET, P. Yield response factors of field crops to deficit irrigation. In: FOOD Agriculture Organization of the United Nations. Deficit irrigation practices. Rome: 2002. Cap. 2, p. 11-16. (Corporate Document Repository 22).

OLIVEIRA, E. C.; CARVALHO, J. de A.; SILVA, W. G. da; REZENDE, F. C.; ALMEIDA, W. F. de. Effects of water deficit in two phenological stages on production of japanese cucumber cultived in greenhouse. Engenharia Agrícola, Jaboticabal, v.31, n.4, p.676-686, jul - ago, 2011.

REICHARDT, K.; TIMM, L. C. Solo, planta e atmosfera: Conceitos, Processos e Aplicação. Barueri: Manole, 2004. 478p.

RODRIGUES, S. B. S.; MANTOVANI, E. C.; OLIVEIRA, R. A. de; PAIVA, H. N. de; ALVES, M. E. B. Necessidades hídricas de mudas de eucalipto na região centro oeste de Minas Gerais. Irriga, Botucatu, v. 16, n. 2, p. 212-223, abril-junho, 2011.

SAUNDERS, L.C.U. Métodos de determinação e variabilidade espacial da condutividade hidráulica sob condições de campo. 1978. 71 p. Tese (Doutorado em
Ciências) - Escola Superior de Agricultura Luiz de Queiroz, Universidade de São Paula, Piracicaba, 1978.

SCHNEIDER, A.A.; MILLER, J.P. Description of sunflower growth stages. Crop Science, v. 21, n. 6, p. 901-903, 1981.

SEZEN, S.M.; YAZARB, A.; KAPURB, B.; TEKINB, S. Comparison of drip and sprinkler irrigation strategies on sunflower seed and oil yield and quality under Mediterranean climatic conditions. Agricultural Water Management, v. 98, p. 1153-1161, 2011.

SILVA, E. N. da; BEZERRA, F. M. L. Evapotranspiração e coeficientes de cultivo da bananeira no Vale do Curu, CE. Revista Ciência Agronômica, Fortaleza, v. 40, n. 2, p. 203-210, abr-jun, 2009.

SNYDER, R.L. Equation for evaporation pan to evapotranspiration conversions. Journal of Irrigation and Drainage, v.118, n.6, p. 977980, 1992.

STEWART, J. I. , DANIELSON, R, E. , HANKS, R T, JACKSON, E. B., HAGAN, R. M., PRUITT, W. O. , FRANKLIN, W. T. , RILEY, J. P. Optimizing crop production through control of water and salinity levels of soil. Logan: Utah Water Research Laboratory, 1977. $191 \mathrm{p}$. 